Canadian

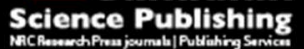

Canadian Journal of Civil Engineering Revue canadienne de génie civil

\title{
Impacts of pool and vegetated banks on turbulent flow characteristics
}

\begin{tabular}{|r|l|}
\hline Journal: & Canadian Journal of Civil Engineering \\
\hline Manuscript ID & cjce-2015-0172.R1 \\
\hline Manuscript Type: & Article \\
\hline Date Submitted by the Author: & 27-Jul-2015 \\
\hline Complete List of Authors: & $\begin{array}{l}\text { Fazlollahi, Atefeh; Isfahan University of Technology, } \\
\text { Afzalimehr, Hossein; Isfahan University of Technology, } \\
\text { Sui, Jueyi; Environmental Engineering, }\end{array}$ \\
\hline Keyword: & Bare banks, pool, turbulence, roughness coefficient, vegetated banks \\
\hline
\end{tabular}

SCHOLARONE ${ }^{\mathrm{m}}$

Manuscripts 


\title{
Impacts of pool and vegetated banks on turbulent flow characteristics
}

\author{
Atefeh Fazlollahi, Graduate student \\ Department of water engineering, Isfahan University of Technology, Isfahan, Iran \\ Email: atefe.fazollahi@gmail.com
}

Hossein Afzalimehr, Professor

Department of water engineering, Isfahan University of Technology, Isfahan, Iran E-mail: hafzali@cc.iut.ac.ir

*Jueyi Sui, Professor

Environmental Engineering Program, University of Northern British Columbia, Canada. *Corresponding author. E-mail: jueyi.sui@unbc.ca 


\title{
Impacts of pool and vegetated banks on turbulent flow characteristics
}

\begin{abstract}
Bed forms and vegetation significantly influence flow characteristics. Macro-scale bed forms, such as pools, result in non-uniformity in flow; vegetation alters turbulence intensity, shear stress and velocity distributions. Up to date, limited work on impacts of pools and vegetated banks on flow characteristics has been reported. Based on experiments carried out in laboratory, this study investigates the effects of pool and vegetated banks on flow velocity, Reynolds stress and turbulence intensity distributions. Results for a channel with pool and vegetated banks (vegetated-bank pool channel) are compared to those for channel with pool but without vegetation on pool banks (bare-bank pool channel). Results show that the combined impacts by vegetated banks and pools will intensify dip phenomenon and change the flow structure and its characteristics. It is also found that near both the pool entry and vegetated banks, estimation of the roughness coefficient is affected by the complex flow conditions. As a consequence, it is difficult to apply the Reynolds-averaged Navier-Stocks equations to interpret the results.
\end{abstract}

Keywords: Bare banks, bedform, pool, turbulence, roughness coefficient, vegetated banks

\section{Introduction}

Pools are characteristic macro-scale bed-forms in many alluvial rivers. In the past halfcentury, interactions of riffle and pool with non-uniform flow have been reported (Leopold et 
al. 1964; Yalin and da Silva 1991; MacVicar and Rennie 2012; MacVicar et al. 2013). Keller and Melhorn (1978) pointed out that the pool and riffle sequence is a fundamental macroscale bed-form of rivers, irrespective of the bed material type; however, the pool and riffle sequence is most commonly associated with gravel and sand-bed rivers. Past experimental studies indicate that pools introduce non-uniformity into flow and alter the instantaneous flow structures. In fact, the non-zero pressure gradient flow over pools affects the mean flow and turbulence components, showing different patterns along a pool for the mean velocity, turbulence intensity and the Reynolds stress distribution (MacVicar and Roy 2007; MacVicar and Rennie 2012, MacVicar et al. 2013). In a pool, the flow depth increases on the entry slope. In middle of pool, the flow becomes uniform. On the exit slope, the flow depth decreases. In the section of the entry slope, decelerating flow and a positive pressure gradient occurs. However, in the section of the exit slope, accelerating flow and a negative pressure gradient occurs. Normally, pools exist in straight reaches due to change in bed geometry and discontinuities in the plan form profiles and play a major role in dissipating energy and controlling erosion of channel bed, manifesting as a vital component of river restoration studies (MacVicar et al. 2013).

In addition to bed-forms, aquatic and riparian vegetation has impacts on the flow characteristics, velocity and Reynolds stress and turbulence intensities. In the past two decades, many studies have been reported on velocity profiles and turbulent characteristics in vegetated channels (López and García 2001; White and Nepf 2007a,b; Afzalimehr and Dey 2009; Nasiri et al. 2011; Afzalimehr et al. 2011; Afzalimehr et al. 2012; Nepf et al. 2013). Vegetation can also obstruct the movement of the contact portion of the bed load and stabilize bed forms (Vanoni 1977). Vegetation protects banks and affects the flow structure near the banks. Nasiri et al. (2010) found that the Reynolds stress distribution computed by the 
Reynolds equation cannot be applied when vegetation affects the flow structure. Afzalimehr et al. (2011) claimed that the maximum turbulence intensity and Reynolds stress occur above the vegetation cover of channel bed. Afzalimehr et al. (2012) indicated that near the vegetated banks, velocity distribution exhibits a wavy shape under accelerating flow and a convex shape under decelerating flow. Nepf et al. (2013) found that vegetation zone produces strong shear at the interface of vegetation and bare bank; generates coherent structures which governs the turbulence and Reynolds stresses between vegetation and bare bed.

To our knowledge, little research work has been conducted to investigate the interaction of pool and vegetated banks on turbulent flow characteristics. The main objective of this paper therefore is to investigate the interaction of vegetated channel banks (vegetation on the flume walls) and the pool bedform (pool-channel) on flow velocity, Reynolds stress and turbulence intensity distributions, by comparing the results with those of pool-channel with bare banks. For this conceptual study in laboratory, the physical model for experiments consists of only one pool in order to separate the influence of vegetation and non-uniform flows (accelerating and decelerating flows) on velocity and turbulence distributions. Finally, the interaction of pool and vegetated banks on estimation of Manning roughness coefficient has been investigated.

\section{Experimental Setup}

Experiments were carried out in the hydraulic laboratory at the Isfahan University of Technology, Iran. The flume for this experimental study was $8 \mathrm{~m}$ long, $0.4 \mathrm{~m}$ wide and $0.6 \mathrm{~m}$ deep. During the experiments, flow depth was controlled by a tailgate located at the end of flume. A pump with a maximum flow capacity of 50 lit/s circulated water from a sump to the 
flume. The pool was constructed in the flume and located $5 \mathrm{~m}$ downstream of the flume entrance to make sure that fully developed flow occurs. In the approaching flow section to the testing section, the flow depth and aspect ratio were $0.2 \mathrm{~m}$ and 2, respectively. According to Carling and Orr (2000), the angle of entrance (proximal) slope and exit (distal) slope of pool bed can be considered equal. The pools were designed two dimensional without span-wise variations to study the effect of longitudinal non-uniformity of bed on the flow structure. Namely, along each cross section of the pool, the elevation of pool bed is the same. The wavelength of two-dimensional bed form was $1.5 \mathrm{~m}$ for each experiment.

A down looking Acoustic Doppler Velocimeter (ADV), developed by NORTEK was used to measure the instantaneous three-dimensional velocity components. Velocities were recorded for each point with a sampling frequency of $200 \mathrm{~Hz}$ to keep the Doppler noise energy level of the signal as low as possible and a sampling volume of $5.5 \mathrm{~mm}^{3}$. For each measurement point, the measurement duration was 120 seconds, resulting in 24000 instantaneous velocity measurements for each point. Due to the presence of intermittent spikes contaminating velocity time series measured by Acoustic-Doppler Velocimeter (ADV), statistical properties and power spectral density of such data sets can have unrealistic values. A powerful technique for detecting and removing spurious spikes from ADV time series is the so-called PhaseSpace-Threshold technique (PST) of Goring and Nikora (2002) (Parsheh et al. 2010). To obtain high quality data from the ADV velocity and turbulence, time series were filtered using WinADV which is a windows-based viewing and post-processing utility for ADV files. This software provides signal quality information in the form of a correlation coefficient (COR) and SNR (signal to noise ratio). Moreover, it has filters such as phase-space threshold despiking. The manufacturer suggests that when COR does not exceed $70 \%$, and SNR is less than $5 \mathrm{db}$, the instantaneous velocity measurements are dominated by acoustic noise and, as a 
rule of thumb, that these measurements should be discarded. To avoid the possible aliasing effect, the data with SNR less than $15 \mathrm{db}$ and COR less than $70 \%$ were discarded and then phase space threshold was used to remove remaining spikes from velocity time series. After filtering, the number of acceptable velocity measurements was at least 20000 for each point. Garcia et al. (2005) claimed that ADV resolution is sufficient to capture a significant fraction of the turbulent kinetic energy of the flow. Therefore, measurements of velocity were made at 14 cross-sections (span-wise) and along three stream-wise axes which are $20 \mathrm{~cm}, 10 \mathrm{~cm}$ and 5 $\mathrm{cm}$ from the wall, respectively. For each velocity profile, 25 to 30 points were measured from the point which is $4 \mathrm{~mm}$ above the bed to the point which is $5 \mathrm{~cm}$ below the water surface.

Gravel with a median grain size diameter of $\mathrm{d}_{50}=10 \mathrm{~mm}$ covered the flume bed, and the bed particles were not movable during measurement. The walls were constructed of plexiglas which covered with vegetation. The flow discharge was kept as constant of $18.5 \mathrm{lit} / \mathrm{s}$ during all experiments. The flow was steady and non-uniform in entry section and exit section of the pool, but was uniform in the middle part of the pool.

On the base of past studies, stems of rice were used to glue on flume walls to simulate vegetation on channel banks (Nasiri et al. 2010; Afzalimehr et al. 2012). The stem density was $400 \mathrm{stems} / \mathrm{m}$ calculated as the number of stems per unit length. To keep the stems being on flume walls under the movement of water, the rice stems were stitched by thin cotton wire over the plastic carpet and then the plastic carpet was glued to the flume walls. In order to make sure that the whole water depth is affected only by vegetation, the length of the stems was $40 \mathrm{~cm}$, more than the maximum water depth in pool channel to obtain a uniform cover of vegetation on the wall. In this way, the effect of vegetation length on roughness coefficient and aspect ratio was isolated. The mean diameter of stems was $0.26 \mathrm{~mm}$, therefore the density of 400 stems per meter could make a reasonable cover ( 4 stems in each centimeter). Although 
rice is not an aquatic plant, most rice fields in Isfahan are located just near river banks. In addition, our investigations confirm that rice's morphological characteristics are similar to vegetation on banks of downstream Zayandeh-rud river. Fig. 1 shows a schematic of the laboratory flume.

Two different runs were made to investigate the interaction of pool-channel with vegetated banks and pool-channel with bare banks on turbulent flow distributions. Table 1 presents a summary of experimental data. A spatially averaging method, based on Smith and Mclean (1977), was used to calculate Froude number and Reynolds number over the pool as shown in Table 1 (Franca et al. 2010). The shear velocity ( $u *$ ) was determined using three methods of Reynolds stress, the log-law and boundary layer characteristics (BLC).

The log-law velocity distribution was used for the inner region velocity data to obtain shear velocity (Afzalimehr and Anctil 2000) based on von Karman's universal constant $(\kappa=0.4)$. The spatially averaged velocity profile was also used to estimate the shear velocity values using the BLC method (Afzalimehr and Anctil 2000). Moreover, shear velocity was estimated by the Reynolds stress distribution (Afzalimehr et al. 2010). Results indicated that there is a good agreement between the value of shear velocity $(u *)$ estimated by means of the Reynoldsstress measurements and that obtained from the BLC method. Hence, the BLC method was applied to analyze the data in this study.

\section{Results}

\subsection{Mean velocity distributions over the pool}


The non-dimensional velocity profiles for three cross-sections of the channel $x=300 \mathrm{~mm}$ (where the flow is decelerating), $x=800 \mathrm{~mm}$ (where the flow is quasi uniform) and $x=1200$ $\mathrm{mm}$ where the flow is accelerating) are presented in Fig.2. Also, Fig.3 presents the depthaveraged velocity in span-wise and vertical directions over the pool. Fig. 4 represents vorticity generation term in two cross-sections of the pool where decelerating flow in $\mathrm{x}=300 \mathrm{~mm}$ and accelerating flow in $\mathrm{x}=1200 \mathrm{~mm}$ occur. The variation of skewness and kurtosis of stream-wise velocity $(u)$ for two different distances from the bed $(10 \mathrm{~mm}$ and $140 \mathrm{~mm})$ near the bank is shown in Fig. 5. From these figures the following results can be observed.

1) Fig. 2 shows that in spite of aspect ratio $(\mathrm{w} / \mathrm{h}=2)$ the dip phenomenon occurs clearly for vegetated bank runs. It means not only aspect ratio, but also vegetation banks play a role in velocity-dip phenomenon. Afzalimehr and Dey (2009) carried out experiments over gravel bed without bedforms, and they found that for a range of aspect ratio from 3 to 4.5 , the position of maximum velocity was not constant at different distances from the bank, changing from a water depth of $z / h=0.2$ at the distance of $2 \mathrm{~cm}$ from the bank to $z / h=0.6$ at the center of the flume. Also, Fig. 2 shows that maximum velocity occurs at a water depth of $z / h=0.2$ for a distance of $5 \mathrm{~cm}$ from the vegetated bank; however, for the distance of $10 \mathrm{~cm}$ from the vegetated banks it occurs at $z / h=0.28,0.38,0.48$ for the three cross-sections located at $x=300 \mathrm{~mm}, x=800 \mathrm{~mm}$ and $1200 \mathrm{~mm}$, respectively. Comparing to results of Afzalimehr and Dey (2009), the results show that the pool-channel has a significant effect on the position of maximum velocity. It can be concluded that at the cross-sections of $x=300 \mathrm{~mm}$ where the flow is decelerating, dip is more than that at the cross-section of $x=1200 \mathrm{~mm}$ where the accelerating flow occurs. This feature is attributed to interaction of vegetation and pressure gradient on flow structure which is different from results of Graf and Altinaka (1998) which for small aspect ratio $\mathrm{W} / \mathrm{h}<5$, the velocity-dip was observed for accelerating flow, but not for the decelerating flow. In 
addition, Fig. 2 shows that the maximum velocity occurs near the bed for all crosssections along the stream-wise axis at the distance of $5 \mathrm{~cm}$ from the vegetated banks. The occurrence of dip-phenomenon is due to secondary currents effect. The secondary currents are generated by anisotropy of turbulence due to the effects of vegetated banks and small aspect ratio. These secondary currents alter the position of the maximum velocity $\left(u_{\max }\right)$ in each velocity distribution. The anisotropy term $\left(v^{\prime 2}-w^{\prime 2}\right) / u_{*}^{2}$ was used to represent the effect of secondary currents by the stream-wise vorticity (Nezu and Nakagawa 1993). Fig. 4 shows that vorticity generation term for vegetated banks case, is less than that of bare banks along the central axis of channel. Also, for acceleration flow $(x=1200 \mathrm{~mm})$, it remains constant for a water depth of $\mathrm{z} / \mathrm{h}>0.3$ for pool-channel with bare banks; however, its decreasing trend continues up to $\mathrm{z} / \mathrm{h}=0.8$ in the case of vegetated banks. The most significant effect of vegetation banks on vorticity generation in central axis of channel can be observed at a water depth of $\mathrm{z} / \mathrm{h}=0.03$ and 0.04 at the crosssections of $x=300 \mathrm{~mm}$ and $\mathrm{x}=1200 \mathrm{~mm}$, respectively.

2) From the mean velocity distributions, it can be seen that the effect of interaction of vegetated banks and pool on velocity distributions is not significant in the inner layer $(z / h<0.3)$ either along the central axis or the near bank axis, but it is considerable in the outer layer $(z / h>0.3)$ where the velocity distributions deviate from each other. In addition, the velocity values along the central axis are larger than those of the near bank for decelerating flow. As one can see, velocity distributions at different distances from the bank for the uniform section $(x=800)$ and accelerating flow $(x=1200)$ are approximately similar.

3) Fig. 3a shows that the span-wise velocity (v) values along stream-wise axis of $5 \mathrm{~cm}$ from the bank are larger than those along the central axis in decelerating flow; however, the inverse case is observed for accelerating flow. This can be explained with formation of 
secondary currents. Although vegetated banks increase the span-wise velocity in both decelerating and accelerating flows in general, the effect of vegetation is more noticeable in decelerating flow. The maximum span-wise velocity is observed in decelerating flow along the stream-wise axis of $5 \mathrm{~cm}$ from the vegetated banks.

4) Fig. 3b shows that vertical velocity (w) along the central axis is higher than the near bank over the pool, showing that downflow and upflow are stronger at the center of channel. Fig. 3 illustrates the downflow (negative values) currents in decelerating flow and the upflow (positive values) currents in accelerating flow. The differences in velocity between the center axis and near bank can be related to the upwelling (accelerating flow) and downwelling (decelerating flow) regions in the water column due to the secondary currents (Albayrak and Lemmin 2011). Therefore, Fig. 3 indicates that secondary currents are stronger at both entry slope and exit slope in comparison with the flat section of the pool (middle section with uniform flow) due to considerable variation of the vertical component of velocity $(w)$. Vegetation on the banks causes an increase in the vertical velocity near the banks; however, its effect in the central axis of flume is low.

5) Skewness quantifies how symmetrical the distribution is and kurtosis quantifies whether the peaky of the data distribution matches the normal distribution. If the skewness is greater than 1.0 (or less than -1.0), the skewness is substantial and the distribution is far from symmetrical. If the distribution is symmetrical, the positive and negative values will balance each other, and the skewness will be close to zero. If the distribution is not symmetrical, the skewness will be positive if the distribution is skewed to the right, and negative if skewed to the left. Fig. 5 shows that velocity distribution follows the normal distribution near the water surface and near the bed for all runs (the skewness is lower than 1). In addition, the skewness values are generally negative which denotes the presence of lower velocity values from the mean value. Positive kurtosis for both 
experiments indicates a relatively peaked distribution. However, negative kurtosis in some sections of pool indicates a relatively flat distribution. The negative values of skewness for bare banks case suggest that diffusion of $u^{\prime} u^{\prime}$ and $w^{\prime} w^{\prime}$ downward along the pool for the depth $140 \mathrm{~mm}$, while some positive values (Fig. 5) indicate that diffusion of $u^{\prime} u^{\prime}$ and $w^{\prime} w^{\prime}$ are upward. The skewness and kurtosis are around zero for the vegetated banks case, showing an equilibrium momentum transfer between the flow and vegetation.

\subsection{Turbulence intensity distributions over the pool}

The contours of root-mean-square (rms) of the stream-wise velocity $(u)$ for bare and vegetated banks runs at the central axis and $5 \mathrm{~cm}$ from bank were presented in Fig. 6 . The generation of strong secondary currents by the joint effect of aspect ratio and vegetation causes greater turbulence near free surface along the axis of $5 \mathrm{~cm}$ from the vegetated banks. However, for bare bank run, along the central axis, the minimum of $u^{\prime}$ occurs near water surface due to weak secondary flows. Fig. 6 shows that turbulence intensity in decelerating flow section is in general greater than that in accelerating flow section. This is due to adverse pressure gradient effect in decelerating flow section.

\subsection{Reynolds stress distribution over the pool}

Fig. 7 shows the Reynolds stress (RS) distribution for three cross-sections of the pool, in which RS distribution depends on the distance from the vegetated banks where the most considerable effect of vegetated banks is observed. The most negative values of Reynolds stress occur near the water surface along the stream-wise axis of $5 \mathrm{~cm}$ from the vegetated bank because the velocity dip occurs at $\mathrm{z} / \mathrm{h}=0.3$ or less and $\mathrm{du} / \mathrm{dz}$ is significantly negative in 
this region. Also, positive values of span-wise velocity (v) contribute strongly to Reynolds stress at $\mathrm{z} / \mathrm{h}>0.3$. Fig. 7 shows a convex distribution of Reynolds stress along the stream-wise axis of $5 \mathrm{~cm}$ from the vegetated bank, which is in agreement with the results of Afzalimehr et al. (2012). In addition, for all experiments, the Reynolds stress values near the vegetated bank were less than those in the center of channel which is in agreement with the results of Macvicar and Rennie $(2009,2012)$. For the uniform flow section of the pool $(\mathrm{x}=800 \mathrm{~mm})$, the Reynolds stress distribution is not uniform either for pool with bare banks or pool with vegetated banks. This is due to strong lateral gradient of the Reynolds stress at the upstream section (decelerating flow section). Perturbation near the banks causes an additional resistance, generating negative values of RS for uniform flow.

\section{4- Resistance coefficient over the pool}

The most frequently used formulas relating open-channel flow velocity to resistance coefficient are the Darcy-Weisbach and Manning formulas:

$$
\begin{aligned}
& V=\sqrt{\frac{8 g}{f}} \sqrt{R S} \\
& V=\frac{K_{n}}{n} R^{2 / 3} S^{1 / 2}
\end{aligned}
$$

in which $V$ is the mean flow velocity of at a cross-section; $n$ and $f$ are the Manning and DarcyWeisbach resistance coefficients, respectively; $R=$ the hydraulic radius, $S=$ the water surface slope; $g=$ the gravity acceleration, and $K_{n}$ is equal to $1\left(\mathrm{~m}^{1 / 2} / \mathrm{S}\right)$ for $V$ and $R$ in SI units.

The resistance coefficients can be related as:

$$
\sqrt{\frac{f}{8}}=\frac{n \sqrt{g}}{R^{1 / 6} K_{n}}
$$


Thus, knowing the value of one resistance coefficient, the corresponding values of the other resistance coefficients can be computed. Garcia (2008) denoted that bed forms play a significant effect on the roughness factor. In this study, we computed the Manning coefficient from the Darcy-Weisbach coefficient over the pool. The roughness coefficients presented in Fig. 8 are cross-sectional roughnesses. Accordingly, instead of using equations (1), (2) or (3) which depends on energy slope, shear velocity was calculated by each velocity profile data using the boundary layer characteristics methods (Afzalimehr and Anctil 2000). In this case the Darcy-Weisbach coefficient can be computed as

$$
\frac{V}{V_{*}}=\sqrt{\frac{8}{f}}
$$

Where $V *$ is the averaged shear velocity of three measured profiles at each section in which shear velocity was computed by the boundary layer characteristics method (Afzalimehr and Anctil 2000). By obtaining $f$, the value of $n$ can be determined using (3).

Fig. 8 shows the results along different stream-wise axes wherein the values of $n$ are roughly between 0.01 and 0.03 . Fig. 8 indicates an increasing trend on the entry slope of the pool (decelerating flow section), afterwards, a quasi-constant value in uniform part of pool and a decreasing trend on the exit slope of the pool where the flow is accelerating. To justify such trends over different parts of the pool, the momentum equation for steady and non-uniform flow in stream-wise direction is written as follow:

$$
\tau=\rho g h S-\rho V h \frac{\partial V}{\partial x}
$$

In decelerating flow (exit slope), $\partial \mathrm{V} / \partial \mathrm{x}$ is negative, while it is positive for accelerating flow (entry slope). Therefore, the shear stress or resistance to flow in decelerating flow is higher than those for accelerating flow, showing an increasing trend for decelerating flow and 
decreasing trend for accelerating flow (Fig. 8). For uniform flow section, $\partial \mathrm{V} / \partial \mathrm{x}=0$, therefore $\tau$ remains constant.

\section{Discussion}

No velocity dip was observed for the pool-channel with bare banks runs for a water depth of $0<z / h<0.8$ (Fig.2) where ADV measurements were obtained, confirming by non-negative values of Reynolds stress (Fig.7). Also, the non-zero mean velocity in vertical direction (w) driven by the secondary flows causes the Reynolds shear stress distribution to deviate from the conventional linear distribution. Therefore, the secondary currents causes such a deviation, leading the location of the maximum velocity to occur below the free surface for vegetated banks runs because the vegetated banks generate strong secondary flows due to decrease in mean velocity and higher turbulence by vegetation along the pool.

Comparison of skewness and kurtosis values for the bare and vegetated banks experiments reveals that the vegetated banks cause lower skewness than that of bare banks runs. For bare banks runs, higher turbulence intensity is observed near the bed; however, for vegetated banks runs, the largest turbulence intensity occurs along the stream-wise axis of $5 \mathrm{~cm}$ from the bank near the free surface. The non-zero values of Reynolds stress (negative values) for the vegetated bank runs shows that vegetation on banks considerably influences the span-wise gradient of Reynolds stress which affects the vertical Reynolds stress $\left(u^{\prime} w^{\prime}\right)$. The Reynolds Averged Navier- Stokes (RANS) equations cannot explain the local shear stress distribution in presence of vegetated banks and the pool because the flow over the pool with bare banks or the vegetated banks channel is influenced by irregular vortex shedding due to non-zero spanwise and stream-wise velocity gradients. The interaction of the span-wise velocity gradient 
due to vegetation roughness causes changes in the traditional linear distribution of Reynolds stress for uniform flow at cross-sections of $\mathrm{x}=800 \mathrm{~mm}$ as well as $\mathrm{x}=300 \mathrm{~mm}$ and $\mathrm{x}$ $=1200 \mathrm{~mm}$, as shown in Fig. 7 .

Comparison of the results of this study with the flow over gravel bed without bedform but with the same vegetated banks (Afzalimehr et al 2012) reveals no negative RS value along the stream-wise axis of $6 \mathrm{~cm}$ from the vegetated banks and the central axis. Based on RANS equation in stream-wise direction, considering the no-slip condition at the bed, it can be written as $\partial P / \partial x=\partial \tau / \partial x$, showing a concave distribution for the cross-section of $\mathrm{x}=1200$ $\mathrm{mm}$ where the flow is accelerating $(\partial P / \partial x<0)$ and a linear distribution for uniform flow at the cross-section of $\mathrm{x}=800 \mathrm{~mm}$ where $\partial P / \partial x=0$. When $\partial P / \partial x<0$, the value $\partial \tau / \partial x$ should be also negative. However, it has a positive trend near the bed, as shown in Fig.7. For the uniform flow $\partial \tau / \partial x=0$ because the stream-wise pressure gradient for the uniform flow is $\partial P / \partial x=0$. However, no linear distribution of RS is observed for flows in pool-channel with bare banks or vegetated banks (Fig.7).

The maximum Manning coefficient values along the central axis of pool-channel with bare banks runs and vegetated banks runs are found to be 0.030 (at decelerating flow section $x=300$ $\mathrm{mm}$ ) for the case of $5 \mathrm{~cm}$ from the vegetated banks due to interaction of adverse pressure gradient $(\operatorname{dev} / d x<0)$ in the pool entry with vegetation. Higher values of Manning coefficient (n) for uniform flow than those of decelerating flow and different trend of (n) along streamwise axis of $5 \mathrm{~cm}$ from the vegetated banks (Fig.8) reveal that RANS equations should be modified by the impacts of vegetation in order to preciously estimate roughness coefficient near the banks. 


\section{Conclusions}

This study shows that the secondary flows modifies the local velocity and turbulence characteristics near the vegetated banks in presence of the pool. Negative values of Reynolds stress and its deviation from traditional linear distribution indicates that the classic roughness coefficient of Manning needs to be treated with caution if it is to be applied to the poolchannel with vegetated banks.

Reynolds Averaged Navier-Stocks equations in stream-wise direction cannot be used to interpret the Reynolds stress pattern for the vegetated banks due to additional roughness of vegetation and strength of shedding vortex which modifies local pattern of turbulence intensities and Reynolds stress. Also, the interaction the wake vortex at the pool entry section with the shedding vortex of vegetated banks makes the distributions of turbulence characteristics to be more complex.

The nature of turbulence in a pool-channel with vegetated banks has yet to be investigated in more details in order to obtain information on the shear layer, wake zone, and separation region. Extension and verification of the results obtained in this study are strongly needed for river restoration projects and to improve fluvial hydraulics models.

\section{References}

Afzalimehr, H. and Anctil, H. 2000. Accelerating shear velocity in gravel bed channels. Journal of hydrological science, IAHS, 45(1): 143-155.

Afzalimehr, H. and Dey, S. 2009. Influence of bank vegetation and gravel bed on velocity and Reynolds stress distributions. International Journal of Sediment Research. 24(2): 236-246. 
Afzalimehr, H., Fazel, E. and Singh, V. J. 2010. Effect of vegetation on banks on distributions of velocity and Reynolds stress under accelerating flow. Journal of Hydrologic Engineering (ASCE).15(9): 708-713.

Afzalimehr, H. Moghbel, R., Ghalichand, J. and Sui, J. 2011. Investigation of turbulence characteristics in channel with dense vegetation over bed. International Journal of Sediment Research.26(3): 269-282

Afzalimehr, H., Fazel, E. and Ghalichand, J. 2012. Effects of accelerating and decelerating flows in a channel with vegetated banks and gravel bed. International Journal of Sediment Research. 27 (2): 188-200.

Albayrak, I. and Lemmin, U. 2011. Secondary Currents and Corresponding Surface Velocity Patterns in a Turbulent Open-Channel Flow over a Rough Bed. Journal of Hydraulic Engineering. ASCE.137(11): 1318-1334.

Carling, P. A. and Orr, H. G. 2000. Morphology of Riffle-Pool Sequences In The River Severn, England. Earth Surface Process Landforms. 25: 369-384.

Franca M.J., Ferreira R.M.L. and Lemmin U. 2010. Double-average methodology applied to turbulent gravel-bed river flows, River Flow 2010 - International Conference on Fluvial Hydraulics, Braunschweig, eds.: Dittrich A., Koll K., Aberle J. \& Geisenhainer P., Bundesanstalt für Wasserbau, pp. 59-66.

Garcia, M. H. 2008. Section 2: Sediment transport and morphodynamics. ASCE manual of practice 110: Sedimentation engineering, M. H.Garcia, ed., ASCE, Reston, Va. 2.21-2.163.

Garcia, C. M., Cantero, M. I., Nino, Y. and Garcia, M. H. 2005. Turbulence measurements with Acoustic Doppler Velocimeters. Journal of Hydraulic Engineering, ASCE. 131(12): 1062-1073.

Graf ,W. H. and Altinakar, M.S. 1998. Fluvial Hydraulics, Flow and Transport Processes in Channel of Simple Geometry. Wiley, New York, NY, USA. 
Goring, D. G. and Nikora, V.I. 2002. Despiking Acoustic Doppler Velocimeter data. Journal of Hydraulic Engineering, ASCE. 128:117-126.

Keller, E. A. and Melhorn W. N. 1978. Rythmic spacing and origin of pools and riffles. Geology Society of Ameraica. Bull. 89: 723-730.

Leopold, L. B., Wolman, M. G. and Miller, J. P. 1964. Fluvial Processes in Geomorphology. W.H. Freeman, San Francisco, 203-215.

López, F. and García, M. H. 2001. Mean flow and turbulence structure of open channel flow through non-emergent vegetation. Journal of Hydraulic Engineering, ASCE. 127(5): 392 402.

MacVicar, B. J., Obach, L. and Best, J. J. 2013. Large-scale coherent flow structures in alluvial pools. In Coherent Flow Structures at Earth's Surface, First edition. Edited by Jeremy G. Venditti, James, L. Best, Michael Church and Richard, J. Hardy. Published by John Wiley \& Sons. pp.243-259.

MacVicar, B. J. and Rennie, C. D. 2012. Flow and turbulence redistribution in a straight artificial pool. Water Resource Research. 48(2), W02503. DOI: 10.1029/2010WR009374.

MacVicar, B. J. and Rennie, C. D. 2009. Lateral distribution of turbulence and secondary currents in non-uniform open channel flow. 33rd IAHR Congress: Water Engineering for a Sustainable Environment Hydraulics. (IAHR) ISBN: 978-94-90365-01-1, pp.1908-1915.

MacVicar, B. J., and Roy, A. G. 2007. Hydrodynamics of a forced riffle pool in a gravel bed river: 1. Mean velocity and turbulence intensity. Water Resource Research. 43, W12401, doi: 10.1029/2006WR005272.

Nasiri Dehsorkhi, E., Afzalimehr, H. and Sui, J. 2010. Effects of vegetation channel banks and gravel size on flow structure. International Journal of Sediment Research, 25: 110118. 
Nasiri, E., Afzalimehr, H. and Singh V. P. 2011. Effect of bed forms and vegetated banks on velocity distributions and turbulent flow structure. Journal Hydrologic Engineering, ASCE. 16(6): 495-507.

Nepf, H., Rominger, J. and Zong, L. 2013. Coherent flow structures in vegetated channels. In Coherent Flow Structures at Earth's Surface, First edition. Edited by Jeremy G. Venditti, James, L. Best, Michael Church and Richard, J. Hardy. Published by John Wiley \& Sons. pp.135-147.

Nezu, I. and Nakagawa. H. 1993. Turbulence in open channel flows. A.Balkema. Rotterdam. Netherland.

Parsheh, M., Sotiropoulos, F., and Porté-Agel, F. (2010). ”Estimation of Power Spectra of Acoustic-Doppler Velocimetry Data Contaminated with Intermittent Spikes.” J. Hydraul. Eng., 136(6), 368-378. doi: 10.1061/(ASCE)HY.1943-7900.0000202.

Smith, J. D. and Mclean, S. R. 1977. Spatially Averaged Flow over a wavy surface. Geophysics Research.83(12):1735-1746.

Vanoni, V. A. 1977. Sedimentation Engineering. ASCE, New York.

White, B. and Nepf, H. 2007a. Shear instability and coherent structures in a flow adjacent to a porous layer. Journal of Fluid Mechanics.593:1-32.

White, B. and H. Nepf. 2007b. A vortex-based model of velocity and shear stress in a partially vegetated shallow channel. Water Res. Res., 44(1): W01412, doi. 10.1029/2006WR005651.

Yalin, M. S. and da Silva, A. M. F. 1991. On the formation of alternate bars, In Sousby, R. and Bettess, R. (Eds), Sand Transport in Rivers, Estuaries and the Sea, Euromech. Colloquium Proceedings 262, pp.171-178. 
Table 1. Flow characteristics

\begin{tabular}{|c|c|c|c|c|c|c|c|c|}
\hline Run & \multirow{2}{*}{$\begin{array}{c}\text { Slope of } \\
\text { crest } \\
\text { degree) }\end{array}$} & $\mathrm{h}(\mathrm{cm})$ & $\begin{array}{c}\text { Vegetated } \\
\text { bank }\end{array}$ & $\mathrm{Fr}$ & \multirow{2}{*}{$\begin{array}{c}\text { Re } \\
\left(\times 10^{4}\right)\end{array}$} & \multicolumn{3}{|c|}{ Shear velocity $(\mathrm{cm} / \mathrm{s})$} \\
\hline 1 & 5 & 20 & No & 0.22 & 2.1 & 1.8 & 1.5 & 1.6 \\
\hline 2 & 5 & 20 & Yes & 0.26 & 2.6 & 1.7 & 2.4 & 1.9 \\
\hline
\end{tabular}

\section{Figure Caption}

Figure 1. Laboratory set up

Figure 2. Dimensionless velocity distributions in entry, middle and exit slopes of pool

Figure 3. Span-wise and vertical mean velocity over the pool in $5 \mathrm{~cm}, 10 \mathrm{~cm}$ from the wall and central axis

Figure 4. Vorticity generation distributions in decelerating and accelerating sections of the pool

Figure 5. Statistical third and fourth moments of stream-wise velocity over the pool

Figure 6. Contour maps of RMS stream-wise velocity

Figure 7. Dimensionless relative Reynolds stress distributions in entry, middle and exit slopes of pool

Figure 8. Manning coefficient over the pool for central axis and $5 \mathrm{~cm}$ from the wall 


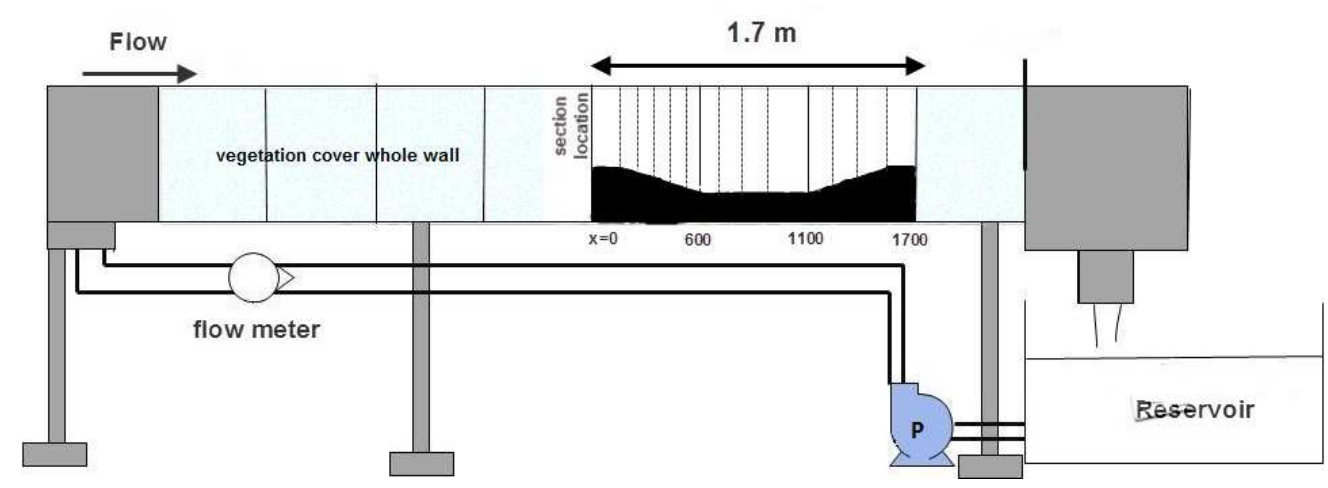

Figure 1.Laboratoary setup 

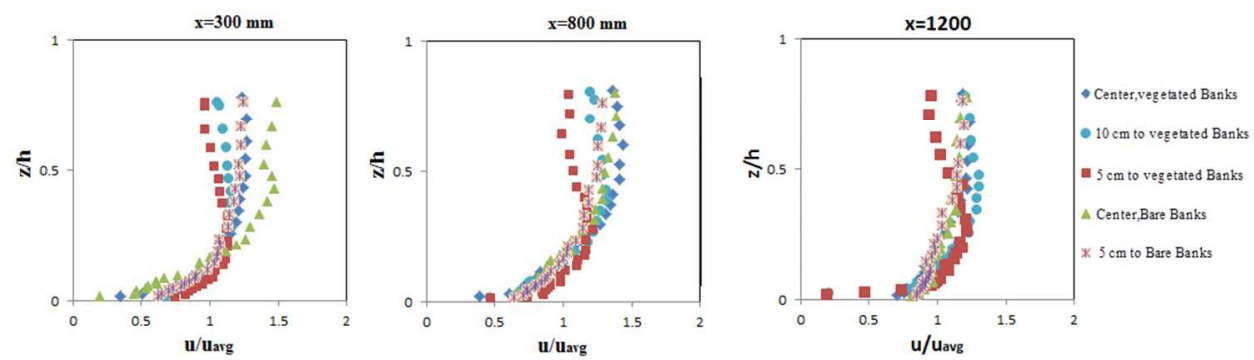

Figure 2. Dimensionless velocity distributions in entry, middle and exit slopes of pool $300 \times 116 \mathrm{~mm}(96 \times 96 \mathrm{DPI})$ 

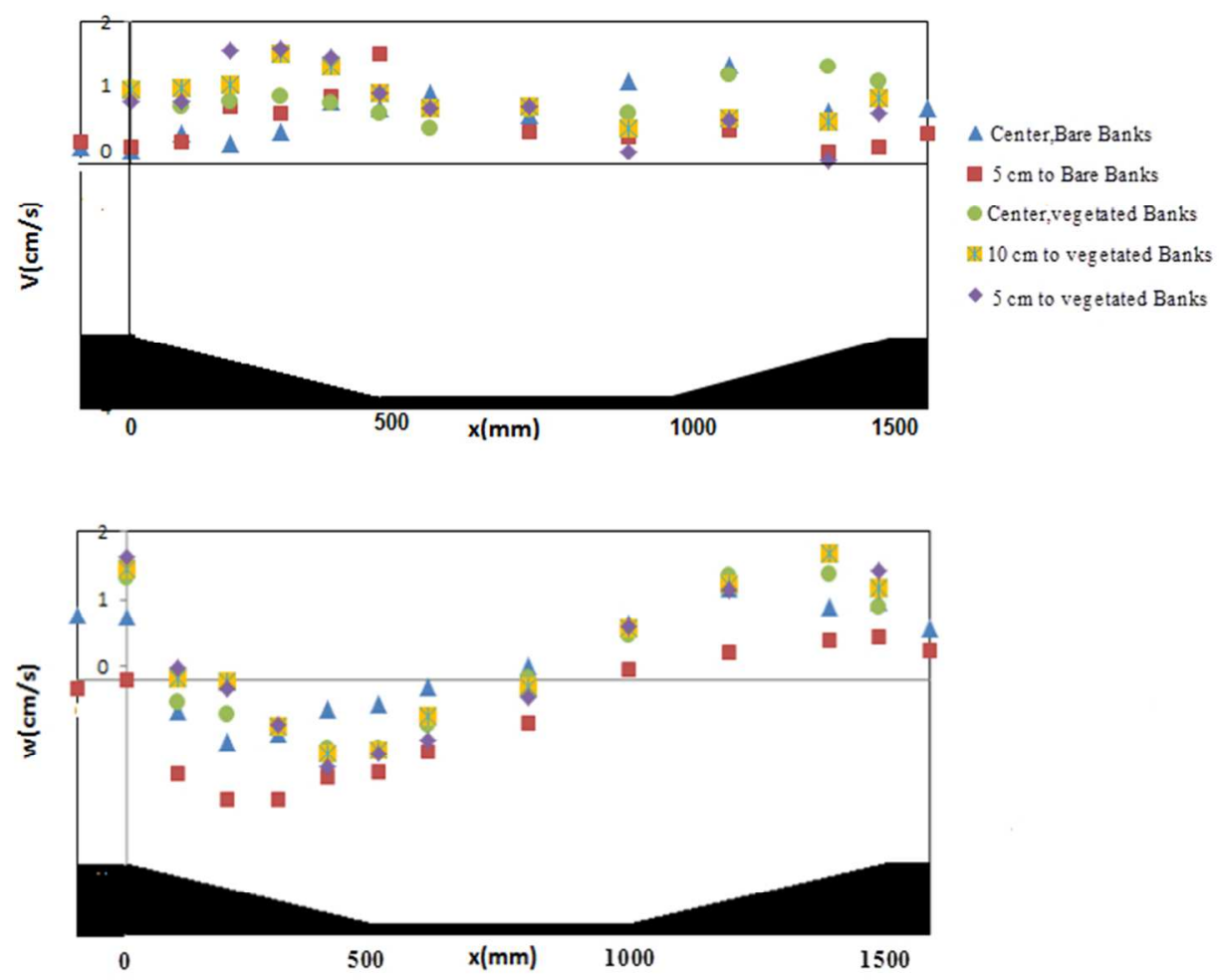

Figure 3. Span-wise and vertical mean velocity over the pool in $5 \mathrm{~cm}, 10 \mathrm{~cm}$ from the wall and central axis $204 \times 172 \mathrm{~mm}(96 \times 96$ DPI) 


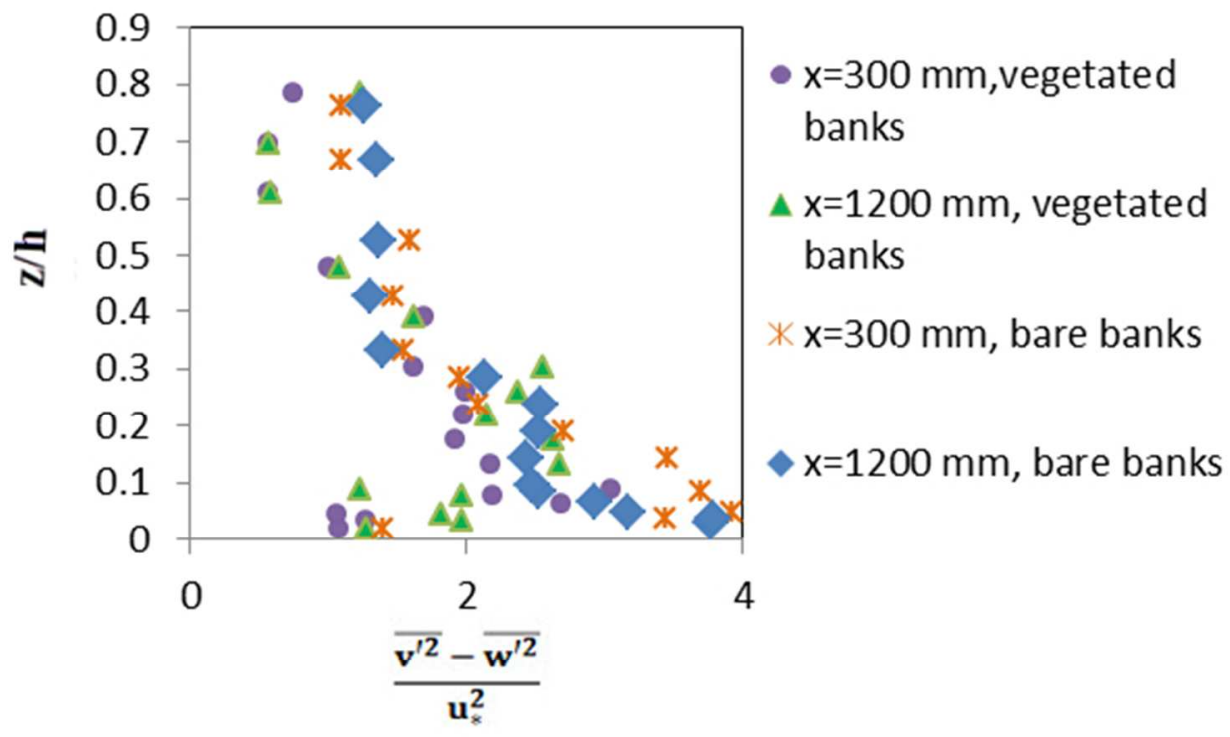

Figure 4. Vorticity generation distributions in decelerating and accelerating sections of the pool $165 \times 109 \mathrm{~mm}(96 \times 96 \mathrm{DPI})$ 


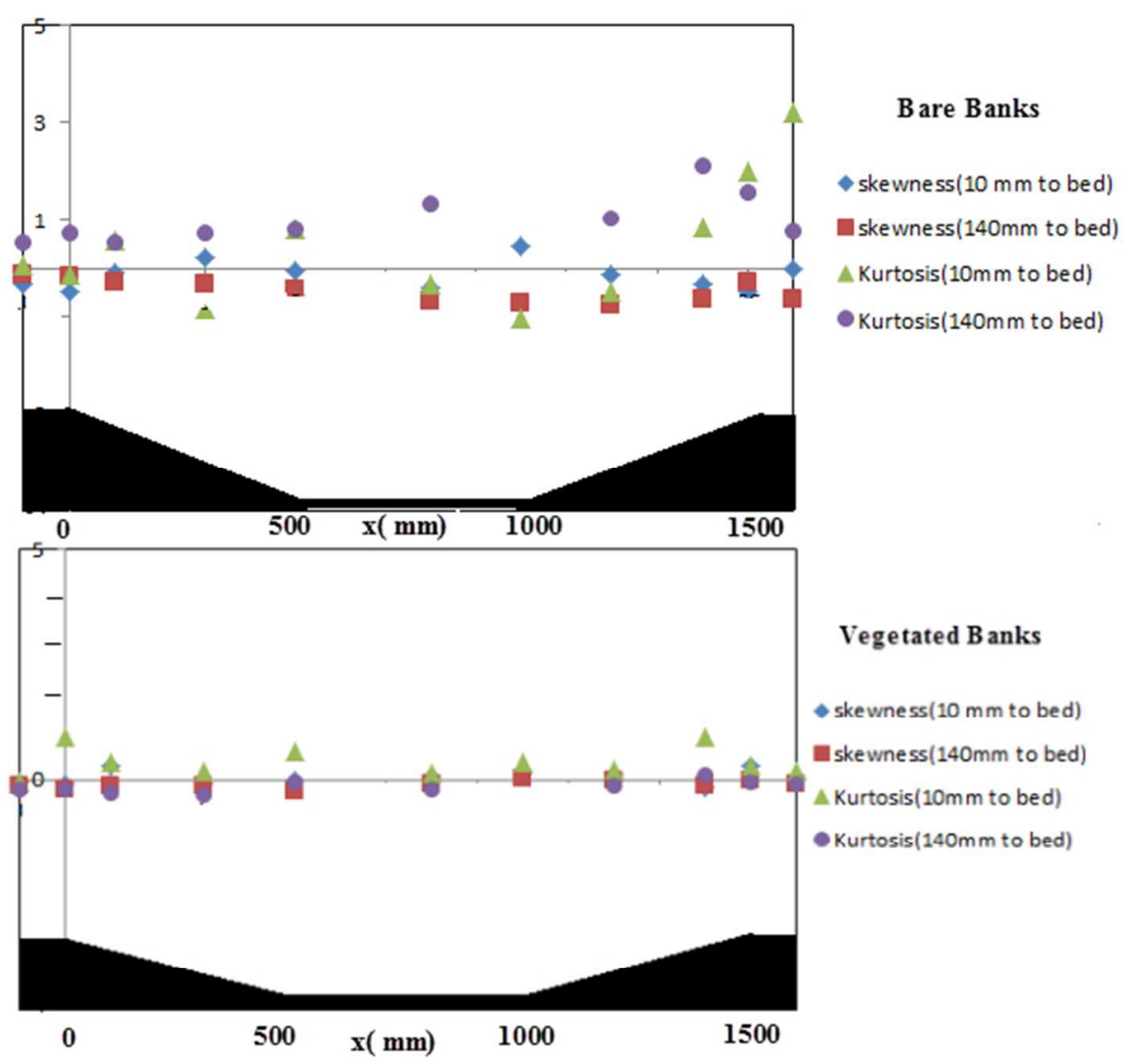

Figure 5. Statistical third and fourth moments of stream-wise velocity over the pool $171 \times 158 \mathrm{~mm}(96 \times 96 \mathrm{DPI})$ 

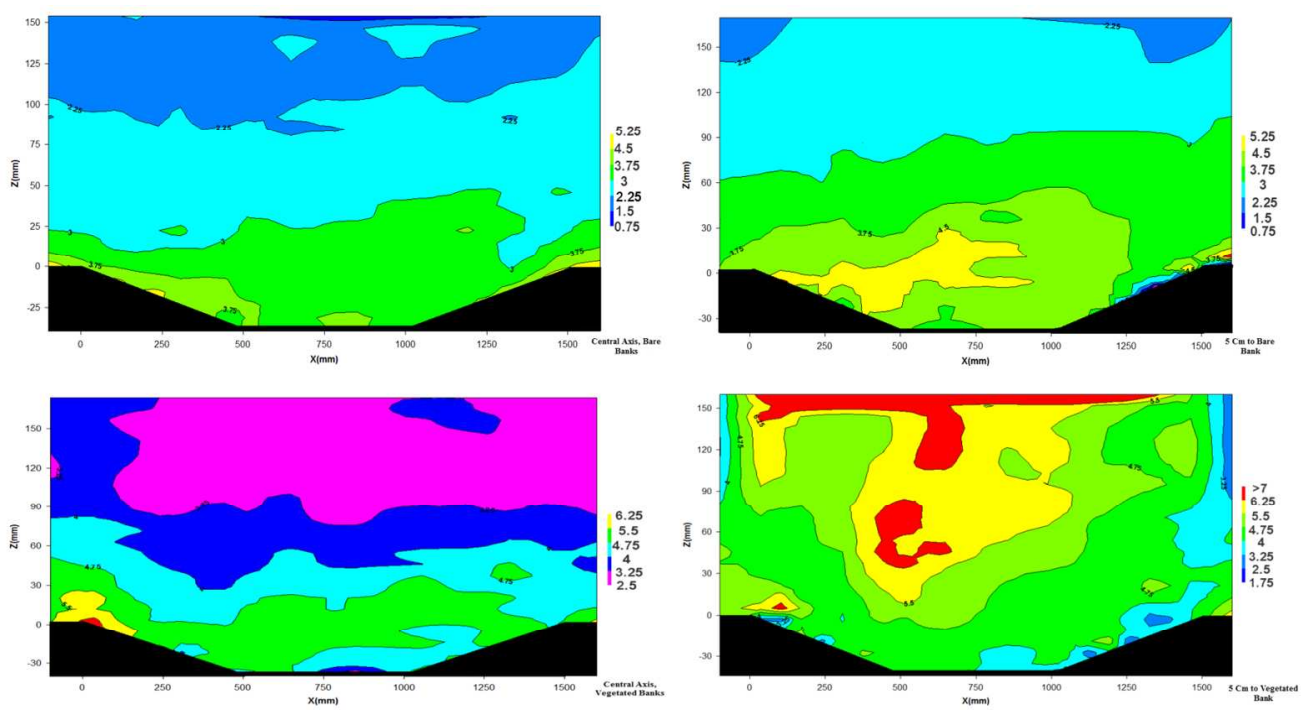

Figure 6. Contour maps of RMS stream-wise velocity $453 \times 260 \mathrm{~mm}(96 \times 96 \mathrm{DPI})$ 

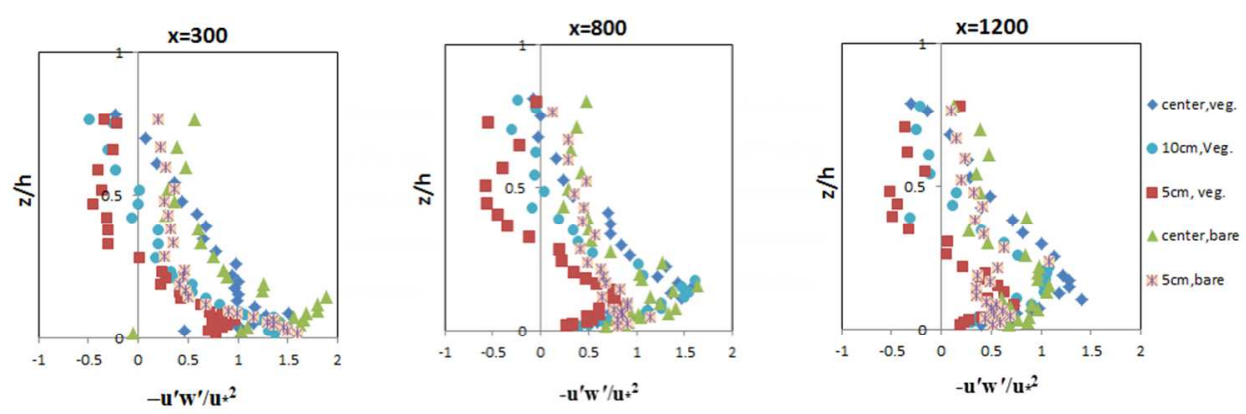

Figure 7. Dimensionless relative Reynolds stress distributions in entry, middle and exit slopes of pool $274 \times 93 \mathrm{~mm}(96 \times 96$ DPI) 